\title{
Antimicrobial resistant bacteria in wild mammals and birds: a coincidence or cause for concern?
}

\author{
Shaun Smith', Juan Wang ${ }^{2}$, Séamus Fanning ${ }^{2}$ and Barry J McMahon ${ }^{1 *}$
}

\begin{abstract}
Background: The emergence and dissemination of antimicrobial resistance (AMR) is a growing concern to public and animal health. The contribution attributable to wildlife remains unclear. In this study two unrelated wildlife species herring gulls (Larus argentatus) and a hybrid deer (Cervus elaphus $x$ Cervus nippon) were investigated for the presence of Escherichia coli expressing an AMR phenotype.

Findings: Bacterial isolates resistant to $\beta$-lactam compounds were identified in both animal species and the production of functional $\beta$-lactamase was confirmed using nitrocefin. The prevalence of resistant isolates was higher in herring gulls (87\%) compared to deer (31\%). Resistance to this class of antibiotic was found only in non-pathogenic $E$. coli in herring gulls and in both pathogenic and non-pathogenic E. coli strains in deer.

Conclusions: The presence of AMR in wildlife has implications for public health, food safety and potable water source protection among others.
\end{abstract}

Keywords: Herring gull, Larus argentatus, Deer, Antimicrobial resistance, Escherichia coli

\section{Findings}

Antimicrobial resistant (AMR) bacteria are a growing problem worldwide for public health, industry and the environment [1]. Emergence of species such as Escherichia coli that are resistant to extended-spectrum ßeta-lactams and fluoroquinolones is cause for serious concern regarding public and animal health [2]. It is virtually impossible to contain bacteria, pathogenic or otherwise, within health-care or food animal production systems as there is movement of these organisms along with mobile genetic elements between domestic, domiciliated and wild environments $[3,4]$. Recent studies reported that antibiotic-resistant bacteria are present in many parts of the globe, including among wild bird species found in remote habitats [5,6]. This presents the possibility of using certain wild animal species as sentinels and potentially a source for the emergence and spread of new AMR profiles. Two such taxa of concern in Ireland are herring gulls (Larus argentatus) and deer. Herring gulls are common in certain seaside towns in Ireland and are opportunistic feeders. AMR E. coli has been reported in

\footnotetext{
* Correspondence: barry.mcmahon@ucd.ie

'UCD School of Agriculture \& Food Science, University College Dublin, Belfield, Dublin 4, Ireland

Full list of author information is available at the end of the article
}

herring gulls previously with the original source being linked to human activity [7]. There has also been a large increase in the range and abundance of deer species in Ireland in recent decades [8] with the increasing likelihood of contact occurring between these animals, food-producing animals and humans. There have been limited studies examining the prevalence of AMR in wild mammals and birds in Ireland. Therefore the aim of this study was to investigate for the prevalence of $E$. coli cultured from the faeces of herring gulls (Larus argentatus) and hybrid deer (Cervus elaphus $x$ Cervus nippon) in Ireland expressing a multi-drug resistant phenotype.

Samples of herring gull faeces were collected from Howth harbour, a suburb of Dublin City, [coordinates $53^{\circ} 23^{\prime} 22.40$ North, $6^{\circ} 04^{\prime} 15.37$ West] while deer faeces samples were collected in the Wicklow National Park, Co. Wicklow [coordinates 530 $05^{\prime} 50.70$ North, 6 ${ }^{\circ} 15^{\prime} 20.05$ West]. Wicklow National Park can be described as upland blanket bog and both of these sites are located on the east coast of Ireland. Thirty individual fresh herring gull and thirty deer faecal samples were collected in June 2012. Sterile swabs were dipped into the recovered faecal samples, swab tips were then broken off into sterile Cary-Blair transport medium, placed into a coolbox 
and cultured same day upon returning to the laboratory being used to inoculate McConkey agar plates. Plates were incubated for $24 \mathrm{~h}$ at $37.5^{\circ} \mathrm{C}$ to recover E. coli. After incubation plates were visually inspected for the presence of typical colonies. Five isolated monoclonal presumptive $E$. coli colonies were picked from each plate and biochemically tested for their indol and citrase reactions. Isolates that tested negative for citrase and positive for indol were confirmed as E. coli and PCR was used to determine their phylogenetic group as described below [9]. Confirmed isolates were then re-streaked onto freshly prepared Trypticase Soy Agar (TSA) and these were subsequently used for nitrocefin disc and antimicrobial resistant tests. Antimicrobial susceptibility testing was performed by disc diffusion [10] on MuellerHinton agar (MHA) using a panel of 5 antimicrobial agents representing 5 different drug classes, including oxacillin $5 \mu \mathrm{g}$, ciprofloxacin $5 \mu \mathrm{g}$, rifampicin $5 \mu \mathrm{g}$, tetracycline $30 \mu \mathrm{g}$ and penicillin $5 \mu \mathrm{g}$. Antimicrobial agents were chosen to give a range of drug classes including a natural antibiotic, a semi synthetic natural antibiotic and bacteriostatic antimicrobial. Confirmed E. coli isolates were inoculated into a $0.85 \%$ physiological saline following which the turbidity was adjusted to $0.5-0.7$ McFarland. A sterile swab was then used to cover $100 \%$ of MHA plate surface. Antimicrobial-containing discs with the drugs indicated above were then placed onto the agar surface and plates were incubated for 24 hours at $37.5^{\circ} \mathrm{C}$. Where zones of inhibition were observed, the corresponding diameter was measured (in $\mathrm{mm}$ ) from 3 different directions using a Vernier callipers and the average of the 3 measurements was recorded [10]. Preparation of DNA and phylogenetic grouping of E. coli isolates was determined by PCR [9]. Nitrocefin disc tests were performed on each confirmed $E$. coli isolate that was phenotypically resistant to oxacillin/penicillin to check for $\beta$-lactamase production. The development of a red colour on the disc was indicative of the production of a $\beta$-lactamase enzyme.

A total of $41 \mathrm{E}$. coli isolates were recovered from the 30 herring gull faecal samples and 51 E. coli isolates were recovered from the 30 total deer faecal samples collected, giving 92 isolates confirmed for study. All isolates were susceptible to ciprofloxacin and only one isolate was resistant to tetracycline. In contrast, all of these isolates were resistant to rifampicin, oxacillin and penicillin. Each type of unique resistance profile generate by an $E$. coli isolate was then phylogenetically typed for pathogenicity, where many isolates shared a similar resistance profile only one was phylo-typed. From the herring gull isolates three isolates were phylogenetic group A and seven were phylogenetic group B1. Only one isolate was in the pathogenic phylogenetic group D. A total of six of the herring gull isolates were positive in the nitrocefin test. From the deer isolates, four were phylogenetic group A and seven were phylogenetic group B1 while six isolates were in the pathogenic phylogenetic group D. A total of 12 of the deer isolates were positive in the nitrocefin test (Table 1). Overall the prevalence of resistant isolates was higher in herring gulls with $87 \%$ of isolates showing some form of resistance as opposed to deer showing $31 \%$.

The presence of $E$. coli that are resistant to antimicrobial compounds in wildlife animals such as herring gull and deer species represents a concern to public health with, as yet unquantified effects. To our knowledge, this data represents the first report of bacteria that are resistant to antimicrobial agents among wild mammals in Ireland. One plausible explanation for this could be the interaction of deer herds in the Wicklow area with livestock and farms however, there is no causal evidence as yet. It has been demonstrated that resistant bacteria are present in both Polar Regions confirming that these organisms have the potential to reach geographical extremes and remote environments $[5,6]$. Nonetheless, an opportunity now exists to use wild-animal species, particularly the birds, as sentinels to monitor the spread of resistant bacteria, since herring gull ecology is well understood. It has been suggested that herring gulls could acquire AMR resistance from human sources and subsequently transfer this resistance to ecosystems previously lacking in resistant bacteria [7,11]. Species in the Laridae family migrate long distances and can act as both symptom and source of resistant bacteria over natural protective bio-barriers such as oceans and mountain ranges. There is the additional concern that spill over of these bacteria of importance to human and animal health, into wild species could result in wildlife hosts functioning as a reservoirs and vectors for reintroduction to the human populations or introduction to farm animals. Future research focused on the role of wild birds and mammals,

Table 1 Summary of genotypic and phenotypic characteristics of AMR E. coli isolates from wildlife sources

\begin{tabular}{|c|c|c|c|c|c|c|c|c|c|c|c|c|}
\hline \multirow[t]{2}{*}{$\begin{array}{l}\text { Wildlife } \\
\text { source }\end{array}$} & \multirow[t]{2}{*}{ Geographic origin } & \multirow[t]{2}{*}{$\begin{array}{l}\text { No. of } E \text {. coli } \\
\text { isolates }\end{array}$} & \multicolumn{5}{|c|}{ AMR profile $^{a}(\%)$} & \multirow[t]{2}{*}{$\begin{array}{l}\text { No. of isolates with } \\
\text { nitrocefin test positive }\end{array}$} & \multicolumn{4}{|c|}{$\begin{array}{l}\text { Confirmed no. of isolates } \\
\text { from each phylo-group }\end{array}$} \\
\hline & & & CIP & OXA & $\mathbf{P}$ & TET & RIF & & A & B1 & B2 & D \\
\hline Herring gulls & Howth harbour & 41 & 0 & 100 & 100 & 0 & 100 & 6 & 3 & 7 & 0 & 1 \\
\hline Hybrid deer & Wicklow National Park & 51 & 0 & 100 & 100 & 1.9 & 100 & 12 & 4 & 7 & 0 & 6 \\
\hline
\end{tabular}

${ }^{a}$ Antimicrobial compounds are abbreviated as follows: CIP, ciprofloxacin; OXA, oxacillin; P, penicillin; TET, tetracycline; RIF, rifampicin.

bPhylo-group: phylogenetic group. 
as a sentinel species contributing to the dissemination of antimicrobial-resistant bacteria is important. An understanding of the selection pressures, evolution and dissemination of resistance genes in pathogenic organisms is not complete without fully understanding the role of wild-species and natural environments in the process [12]. AMR has been subject to substantial research efforts however, it still remains a massive global public health challenge. Effective antimicrobial therapy using the available arsenal of drugs is important to protect animal and human in public health into the future. Thus a complete understanding of the role played by antimicrobial-resistant bacteria in the domestic, domicilicated and wild environments is required to provide scientifically-sound mitigation measures capable of addressing this public health challenge.

\section{Competing interests}

The authors declare that they have no competing interests.

\section{Authors' contributions}

SS performed the sampling, analysis and wrote the draft of this report. SF and BJMCM supervised all stages of the work presented in this report and critically read the report. JW assisted in the analysis. All authors read and approved the final manuscript.

\section{Acknowledgements}

This work derives from M.Sc. studies in Wildlife Conservation and Management at University College Dublin. Funding for this research project was through University College Dublin Seed Funding 2012- Horizon Scanning and UCD School of Agriculture and Food Science Research and Innovation Committee start up grant 2012.

\section{Author details}

'UCD School of Agriculture \& Food Science, University College Dublin, Belfield, Dublin 4, Ireland. ' UCD Centre for Food Safety, UCD School of Public Health, Physiotherapy \& Population Science, University College Dublin, Belfield, Dublin 4, Ireland.

Received: 22 January 2014 Accepted: 8 April 2014

Published: 25 April 2014

\section{References}

1. World Health Organisation: W.H.O Global Strategy for the Containment of Antimicrobial Resistance Executive Summary. Geneva, Switzerland: World Health Organisation; 2001.

2. Karczmarcyzk M, Abbott Y, Walsh C, Leonard N, Fanning S: Characterisation of multidrug-resistant escherichia coli isolates from animals presenting at a University Veterinary Hospital. Appl Environ Microbiol 2011, 77:7104-7112.

3. Gulliver MA, Bennett M, Begon M, Hazel SM, Hart CA: Enterobacteria: antibiotic resistance found in wild rodents. Nature 1999, 401:233-234.

4. Collignon P, Aarestrup FM: Extended-spectrum beta-lactamases: food, and cephalosporin use in food animals. Clin Infect Dis 2007, 44:1391-1392.

5. Sjölund M, Bonnedahl J, Hernandez J, Bengtsson S, Cederbrant G, Pinhassi J, Kahlmeter $\mathrm{G}$, Olsen B: Dissemination of multidrug-resistant bacteria into the arctic. Emerg Infect Dis 2008, 14:70-72.

6. Hernández J, Stedt J, Bonnedahl J, Molin Y, Drobni M, Calisto-Ulloa N, Gomez-Fuentes C, Astorga-España MS, González-Acuña D, Waldenström J, Blomqvist M, Olsen B: Human-associated Extended Spectrum $\beta$-Lactamase (ESBL) in the antarctic. Appl Environ Microbiol 2012, 76:2056-2058.

7. Bonnedahl J, Drobni M, Gauthier-Clerc M, Hernandez J, Granholm S, Kayser Y, Melhus A, Kahlmeter G, Waldenström J, Johansson A, Olsen B: Dissemination of Escherichia coli with CTX-M Type ESBL between humans and yellow-legged gulls in the South of France. Plos One 2009, 4:e5958.
8. Carden RF, Carlin CM, Marnell F, McElholm D, Hetherington J, Gammell MP. Distribution and range expansion of deer in Ireland. Mammal Rev 2011, 41:313-325.

9. Clermont O, Bonacorsi S, Bingen E: Rapid and simple determination of Escherichia coli phylogenetic group. Appl Environ Microbiol 2000, 66:4555-4558.

10. CLSI: Performance standards for Antimicrobial Susceptibility Testing: 21st Informational Supplement, CSLI Document M100-S21. Wayne PA: Clinical and Laboratory Standards Institute; 2011.

11. Stedt J, Bonnedahl J, Hernandez J, Drobni M, McMahon BJ, Hasan B, Olsen B, Waldenström J: Antibiotic resistance patterns in Escherichia coli from gulls in nine European countries. Infect Ecol Epidemiology 2014, 4:21565.

12. Allen HK, Donato J, Wang HM, Cloud-Hansen KA, Davies J, Handelsman J: Call of the wild: antibiotic resistance in natural environments. Nat Rev Microbiol 2010, 8:251-259.

doi:10.1186/2046-0481-67-8

Cite this article as: Smith et al: Antimicrobial resistant bacteria in wild mammals and birds: a coincidence or cause for concern? Irish Veterinary Journal 2014 67:8.

\section{Submit your next manuscript to BioMed Central and take full advantage of:}

- Convenient online submission

- Thorough peer review

- No space constraints or color figure charges

- Immediate publication on acceptance

- Inclusion in PubMed, CAS, Scopus and Google Scholar

- Research which is freely available for redistribution 